\title{
Towards absorption spectroscopy by means of mid-infrared supercontinuum generation in a step index tellurite fiber
}

\author{
Arnaud Lemière ${ }^{1}$, Anthony Maldonado ${ }^{1}$, Frédéric Désévédavy ${ }^{1}$, Bertrand Kibler ${ }^{1}$, \\ Pierre Mathey ${ }^{1}$, Grégory Gadret ${ }^{1}$, Jean-Charles Jules ${ }^{1}$, Nguyen Phuoc Trung Hoa ${ }^{2}$, \\ Takenobu Suzuki ${ }^{2}$, Yasutake Ohishi ${ }^{2}$ and Frédéric Smektala ${ }^{1}$ \\ ${ }^{1}$ Laboratoire Interdisciplinaire Carnot de Bourgogne, UMR 6303 CNRS-UBFC, 9 av. Alain Savary, BP \\ 47870, 21078 Dijon, France; \\ ${ }^{2}$ Research Center for Advanced Photon Technology, Toyota Technological Institute 2-12-1, Hisataka, \\ Tempaku, Nagoya 468-8511, Japan; \\ sd15501@ toyota-ti.ac.jp (K.N.); takenobu@toyota-ti.ac.jp (T.S.); ohishi@toyota-ti.ac.jp (Y.O.) \\ E-mail: frederic.smektala@u-bourgogne.fr
}

Received xxxxxx

Accepted for publication $\mathrm{xxxxxx}$

Published xxxxxx

\begin{abstract}
We report on mid-infrared gas spectroscopy measurements by means of the supercontinuum absorption spectroscopy method. We developed a 80-MHz-repetition-rate mid-infrared supercontinuum light source with an average power of $40 \mathrm{~mW}$ generated through nonlinear propagation of 200 -fs pulses in a 10-cm-long segment of step-index tellurite fiber. A compact multipass cell is used for analyzing absorption of $\mathrm{CO}_{2}$ and $\mathrm{CH}_{4}$ gases and their mixture in the 2-3.5 $\mu \mathrm{m}$ spectral range. Experimental results are compared to the HITRAN database.
\end{abstract}

Keywords: supercontinuum absorption spectroscopy; mid-infrared light sources; tellurite glasses; optical fibers

\section{Introduction}

Mid- and Long-Wave Infrared (MIR and LWIR) are two spectral regions (2-8 $\mu \mathrm{m}$ for MIR and 8-17 $\mu \mathrm{m}$ for LWIR) of great interest for sensing applications because of many chemical species spectral signature located between 1 and $18 \mu \mathrm{m}$ [1-3]. Especially, carbon dioxyde $\left(\mathrm{CO}_{2}\right)$ and methane $\left(\mathrm{CH}_{4}\right)$ are two greenhouse pollutants absorbing in both MIR and LWIR regions. $\mathrm{CO}_{2}$ absorbs light at 2, 2.7, 4.26, $4.84 \mu \mathrm{m}$ in the MIR region. In the LWIR region, one large absorption band is located between 13.2 and $17 \mu \mathrm{m}$ with a maximum peak at $15 \mu \mathrm{m}$. $\mathrm{CH}_{4}$ presents narrow absorption bands centered at 1.3, 1.65, 2.36, 2.58 and $6.5 \mu \mathrm{m}$ as well as two large absorption bands from 3.11 to $4.12 \mu \mathrm{m}$ (maximum peak at $3.27 \mu \mathrm{m}$ ) and from 7.15 to $8.5 \mu \mathrm{m}$ (maximum peak at $7.66 \mu \mathrm{m}$ ) [4]. Table 1 summarizes the different absorption bands of these two chemical species and gives the corresponding line intensities expressed in $\mathrm{cm}^{-1} /\left(\right.$ molec. $\left.\mathrm{cm}^{-2}\right)$. This unit represents the integral of the absorption band relative to the volume density of molecules at a given pressure. 
Table 1. Absorption bands of $\mathrm{CO}_{2}$ and $\mathrm{CH}_{4}$ between 1 and $17 \mu \mathrm{m}$ with the corresponding line intensities.

\begin{tabular}{c|c} 
Wavelength $(\boldsymbol{\mu m})$ & $\begin{array}{c}\text { Line intensities } \\
\left(\mathbf{c m}^{-1} /\left(\mathbf{m o l e c}^{-\mathbf{c}}\right)\right) \mathbf{x} \mathbf{1 0}^{-22}\end{array}$ \\
\hline \multicolumn{2}{|c}{$\mathbf{C O}_{2}$} \\
\hline $\mathbf{2 . 0}$ & 13.3 \\
\hline $\mathbf{2 . 6 8}$ & 580 \\
\hline $\mathbf{2 , 7 6}$ & 390 \\
\hline $\mathbf{4 . 2 6}$ & 34951.0 \\
\hline $\mathbf{4 . 8 4}$ & 2.06 \\
\hline $\mathbf{1 3 . 2 - 1 7}$ & 2967.2 \\
\hline \multicolumn{2}{|c}{} \\
\hline $\mathbf{1 . 3}$ & 1.6 \\
\hline $\mathbf{1 . 6 5}$ & 15.6 \\
\hline $\mathbf{2 . 3 6}$ & $\mathrm{CH}_{4}$ \\
\hline $\mathbf{2 . 5 8}$ & 52.6 \\
\hline $\mathbf{3 . 1 1 - 4 . 1 2}$ & $2083.05(@ 3.27 \mu \mathrm{m})$ \\
\hline $\mathbf{6 . 5}$ & 8.4 \\
\hline $\mathbf{7 . 1 5 - 8 . 5}$ & $976.0(@ 7.5 \mu \mathrm{m})$ \\
\hline
\end{tabular}

From Table 1, we notice that line intensities are generally increasing as long as we increase the wavelength from near-infrared to MIR. There is a factor 2600 by comparing the line intensities centered at $2.0 \mu \mathrm{m}$ and at $4.26 \mu \mathrm{m}$ for $\mathrm{CO}_{2}$. For $\mathrm{CH}_{4}$, there is a factor 1300 between the line intensities located at $1.3 \mu \mathrm{m}$ and the ones around 3.11-4.12 $\mu \mathrm{m}$. These values confirms the interest that lies gas absorption spectroscopy in the 3-5 $\mu \mathrm{m}$ atmospheric window (see figure 1).

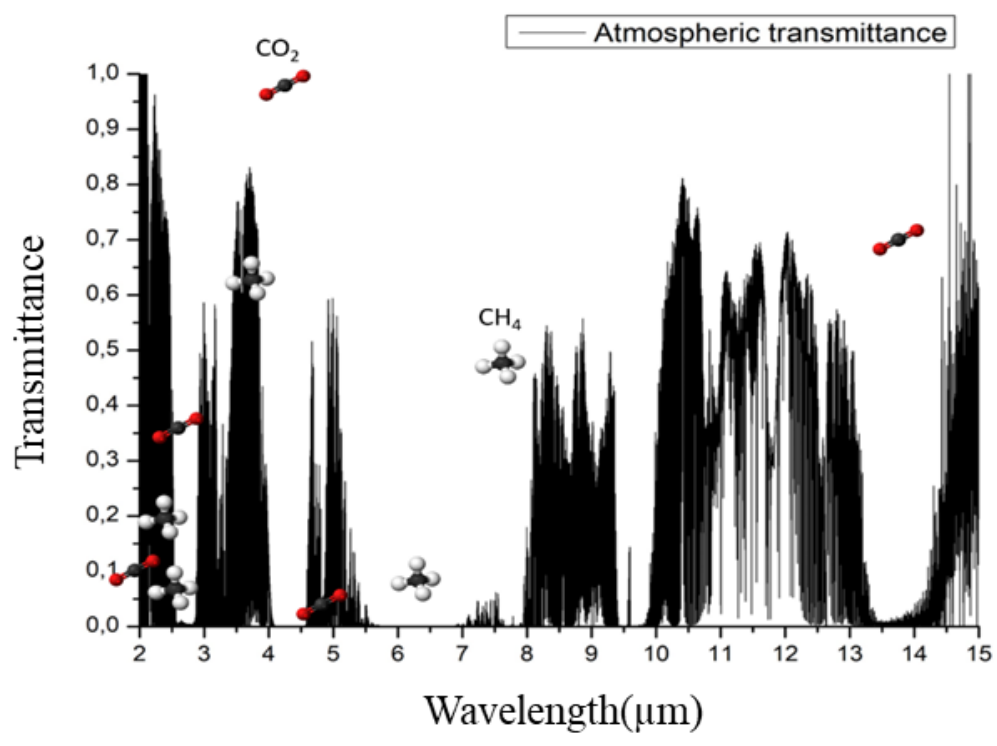

Figure 1. Atmospheric spectrum (black) [5] compared to line intensities of methane and carbon dioxide [4]

Supercontinuum absorption spectroscopy (SAS) is a powerful technique for multi-species analysis of a gas mixture or liquids. This method has already been extensively studied in various configurations (open paths or local sensing) [6, 7]. Nowadays, it mainly consists in the developpement of suitable fiber-based supercontinuum (SC) light sources according to the detection spectral range, to benefit from the higher power of SC pulsed sources than black body radiators. Note that the addition of a strongly-dispersive propagation stage of SC pulses offers the possibility of time-domain based broadband spectroscopy [8, 9]. The recent developpment of fiber-based MIR light sources has then largely extended the spectral range of applications of SAS where many gases exhibit stronger absorption lines [10]. It is also worth mentionning that one can combine photoacoustic detection with SAS, thus providing higher sensitivity than conventional Fourier transform infrared (FTIR) spectrometers [11, 12]. 
We previously reported on SAS measurements of $\mathrm{CH}_{4}$ performed between 1 and $2.5 \mu \mathrm{m}$ with a SC generated in a $75 \% \mathrm{TeO}_{2}$ $15 \% \mathrm{ZnO}-5 \% \mathrm{Na}_{2} \mathrm{O}-5 \% \mathrm{ZnF}_{2}(\%$ molar) microstructured tellurite fiber [13]. Because of the better understanding of aging issues of tellurite glasses [14] in particular in the 2.5-3.5 $\mu \mathrm{m}$ range $(\mathrm{OH}$ absorption), the development of all-solid tellurite fibers appears now essential. Besides, it has been demonstrated that the simple step-index design allows to overcome aging issue, and it offers large capabilities in controlling the fiber dispersion properties and subsequent SC generation [15, 16, 17], just by slightly varying the core size and refractive index difference between core and cladding.

In this work we demonstrate the application of such tellurite fiber-based supercontinuum sources for multi-species analysis of a gas mixture by means of the SAS method in the $2-3.5 \mu \mathrm{m}$ spectral range. To this regard, we make use of a compact multipass cell (70cm-long optical path length, 8 reflexions on gold mirror) and a convential FTIR spectrometer. First, we describe the tellurite glass preparation, fiber fabrication, and the resulting fiber properties as well. Next, we investigate supercontinuum absorption spectroscopy for detection of $\mathrm{CO}_{2}$ and $\mathrm{CH}_{4}$ gases. We analyze the response to nominal gas concentrations and then apply our SAS setup for sensing gas mixtures.

\section{Glass preparation and fiber properties}

The step-index tellurite fiber is developped by means of conventionnal built-in-casting and rod-in-tube methods as described in Ref. [18]. Two compatible glasses are selected to develop a small-core step-index tellurite fiber (with core diameter below $5 \mu \mathrm{m}$ for flexible dispersion engineering) : TZNF and TZNG for core and clad glasses, respectively. The composition of TZNF core glass is $80 \mathrm{TeO}_{2}-5 \mathrm{ZnO}-10 \mathrm{Na}_{2} \mathrm{O}-5 \mathrm{ZnF}_{2}$ (molar fraction) and the composition of TZNG clad glass is $60 \mathrm{TeO}_{2}-5 \mathrm{ZnO}^{-20 \mathrm{Na}_{2} \mathrm{O}-}$ $15 \mathrm{GeO}_{2}$ (molar fraction). These two glasses have a good thermal and optical compatibility (see Table 2). Their optical index difference is about 0.13 at $633 \mathrm{~nm}(0.12$ at $1550 \mathrm{~nm})$ and the difference between both glass transition temperatures is only $8{ }^{\circ} \mathrm{C}$. Furthermore, the thermal expansion coefficients are very similar with a difference of $3.7 \times 10^{-6}{ }^{\circ} \mathrm{C}^{-1}$, thus allowing an excellent compatibility for co-drawing.

Table 2. Principal properties of the tellurite glasses used for fabrication of our step-index fiber.

\begin{tabular}{|c|c|c|c|c|c|}
\cline { 2 - 6 } \multicolumn{1}{c|}{} & $\mathbf{n}(\mathbf{6 3 3} \mathbf{~ n m})$ & $\mathbf{n}(\mathbf{1 0 6 4} \mathbf{~ n m})$ & $\mathbf{n}(\mathbf{1 5 5 0} \mathbf{~ n m})$ & $\mathbf{T g}\left({ }^{\circ} \mathbf{C}\right)$ & $\boldsymbol{\alpha}\left(\mathbf{x 1 0} \mathbf{6}^{\circ} \mathbf{C}^{-\mathbf{1}}\right)$ \\
\hline TZNF & 2.037 & $/$ & 1.989 & 280 & 16.7 \\
TZNG & 1.905 & 1.872 & 1.867 & 272 & 13.0 \\
\hline
\end{tabular}

The synthesis of the glass preform is realized under pure $\mathrm{O}_{2}$ atmosphere by means of a furnace connected to a dry air glove box. This avoids water contaminations and reduces the amount of $\mathrm{OH}$ residual groups in the glass matrix. To improve the purification of our core glass, we substituted $5 \%$ of zinc oxide by zinc fluoride [18-21]. OH groups will react with $\mathrm{ZnF}_{2}$ to produce $\mathrm{HF}$ (and $\mathrm{ZnO}$ ), evacuated by the constant furnace $\mathrm{O}_{2}$ gas flow $(2 \mathrm{~L} / \mathrm{min}$ ). This gas flow is used to guarantee the oxidation conditions during synthesis. The two glasses are synthesized from high purity precursors provided by Fox chemicals, $5 \mathrm{~N}$ for $\mathrm{TeO}_{2}, \mathrm{GeO}_{2}, \mathrm{ZnO}$ and $6 \mathrm{~N}$ for $\mathrm{Na}_{2} \mathrm{CO}_{3}$. Alfa Aesar $4.5 \mathrm{~N} \mathrm{ZnF} 2$ is also used. Both melted glasses are quenched into a brass preheated mold at $240{ }^{\circ} \mathrm{C}$ after a synthesis at $900{ }^{\circ} \mathrm{C}$ during around $1 \mathrm{~h} 30$. The resulting preform is then annealed for 8 hours at $270{ }^{\circ} \mathrm{C}$. We obtain a $45 \mathrm{~mm}$-long and $16 \mathrm{~mm}$-large cylindrical preform [18].

The large-core step-index fiber preform (core-clad ratio $\approx 50 \%$ ) from the build-in-casting stage is used to manufacture capillaries and measure fiber losses (see figure $2 \mathrm{a}$ ). The fiber under test has an outer diameter of $150 \mu \mathrm{m}$ and a core diameter of $70 \mu \mathrm{m}$. The infrared attenuation spectrum of the large-core step-index fiber was obtained by using the cutback method on several meters-long fiber samples with a FTIR spectrometer (NICOLET 6700) working in the 1-5 $\mu$ m range. For technical purposes, an external halogen lamp emitting from 0.1 to $5 \mu \mathrm{m}$ was used as the light source. The attenuation of the fiber exhibits low losses (below $1 \mathrm{~dB} / \mathrm{m}$ between 1.5 and $2.8 \mu \mathrm{m}$ ). Its attenuation increases until $8 \mathrm{~dB} / \mathrm{m}$ at $4 \mu \mathrm{m}$. We observe that the $\mathrm{OH}$ residual groups between 3 and $4 \mu \mathrm{m}$ are very low. Considering the absorption coefficient of the $\mathrm{OH}$-group in silica $\left(\varepsilon_{\mathrm{OH}}=49,1\right.$ $\times 10^{3} \mathrm{~cm}^{3} \mathrm{~mol}^{-1} \mathrm{~cm}^{-1}$ ) [20,22] glass we estimate the amount of $\mathrm{OH}$ residual groups at a level below 0.4 ppm. Another clad-glass preform is synthesized and then drilled at the convenient diameter to insert inside a capillary from the previous large-core preform. An additional drawing process is then required to fabricate a small-core step-index fiber. The resulting fiber is chosen with an external diameter of $150 \mu \mathrm{m}$, which corresponds to a core diameter of $3.5 \mu \mathrm{m}$. This particular value of core diameter gives rise to low and flat anomalous dispersion in the $2-2.5 \mu \mathrm{m}$ spectral range (as shown in figure $2 \mathrm{~b}$ ) as well as strong optical confinement [15], which is fully relevant for SC generation with sub-nanojoule femtosecond pump pulses located beyond $2 \mu \mathrm{m}$ 
[16]. The impact of pumping wavelength and core diameter on SC bandwidth and coherence was investigated in detail in Ref. [16]. It was shown that coherent MIR supercontinuum generation can be obtained for various dispersion regimes and nonlinear propagation over $10 \mathrm{~cm}$, provided that a moderate injected input power is used. More particularly, the optimized dispersion profile (figure $2 \mathrm{~b}$ ) for SC generation is the one resulting from the $3.5 \mu \mathrm{m}$ core with two close zero-dispersion wavelengths (and pumping into the anomalous dispersion), while SC coherence is preserved for input pulse energy about a few hundreds of $\mathrm{pJ}$ (i.e., in the present case below 3-kW peak power for 200-fs pulses). Such a configuration is then chosen in the following SAS experiments for enhanced pulse-to-pulse stability over the whole SC spectrum.
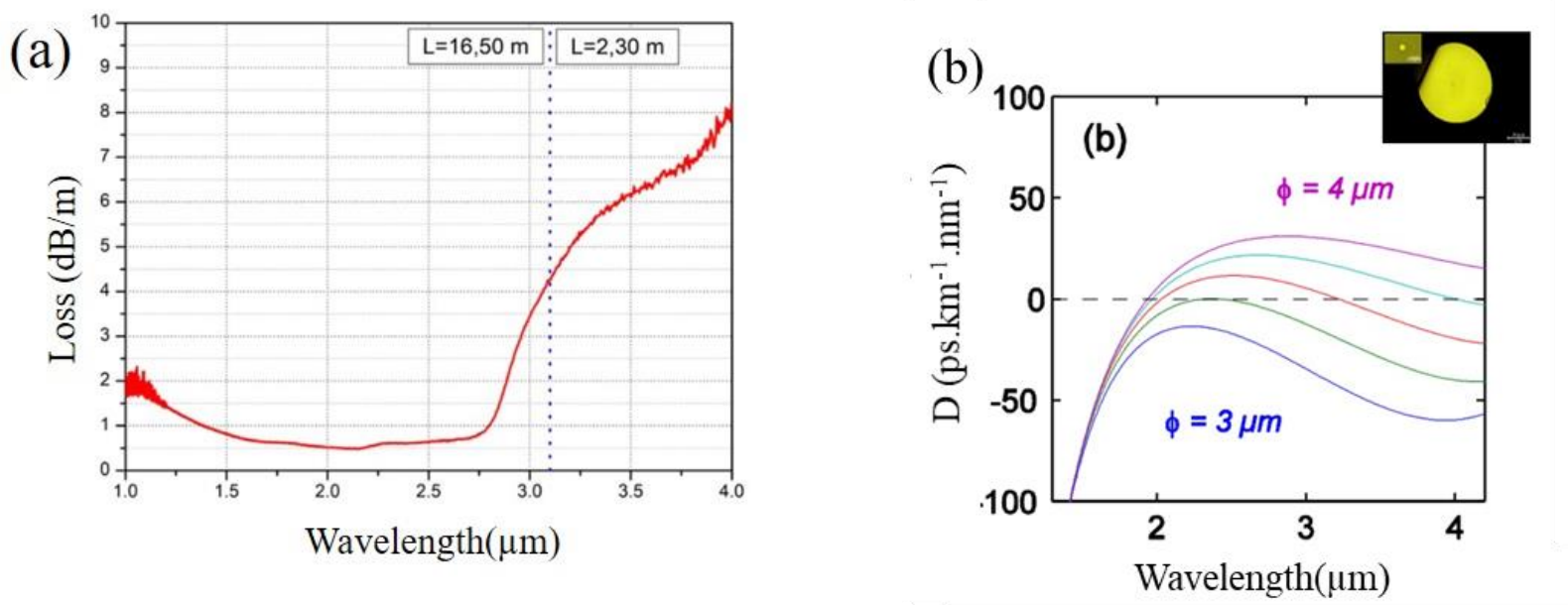

Figure 2. (a) Attenuation of the large core step-index fiber. (b) Wavelength-dependent curves of dispersion parameter $D$ of our step-index fiber design for the following core diameters $\varnothing=3.0,3.25,3.5,3.75,4.0 \mu m$ (Inset: corresponding image of the small-core fiber cross section).

\section{Experimental setup of supercontinuum absorption spectroscopy}

The experimental set-up of SAS is depicted in figure 3. A Ti:Sapphire laser pumps an optical parametric oscillator (OPO) that delivers 200-fs idler pulses at a repetition rate of $80 \mathrm{MHz}$ and with an average power about $200 \mathrm{~mW}$ in the $2.2-2.4 \mu \mathrm{m}$ spectral window. A half-wave plate is inserted between the laser and the tellurite fiber to excite the fiber under test along a defined polarization axis. A silica microscope objective allows an efficient beam coupling (2.5-kW injected peak power) into the fundamental mode of our step-index tellurite fiber. A 10-cm-long segment of tellurite fiber is then carefully cleaved with a scalpel blade and the output SC signal is collimated with a chalcogenide lens. The light beam is re-focalized in the multipass cell with a $10-\mathrm{cm}$ focal length $\mathrm{CaF}_{2}$ lens. The multipass cell provides an optical path length of $70 \mathrm{~cm}$ for 8 reflexions on gold mirrors. The output signal of the cell is collimated with a silver off-axis parabolic mirror and then focalized in an $\mathrm{InF}_{3} \mathrm{multimode}$ fiber (with high transmission between 0.35-5.5 $\mu \mathrm{m}$ ) connected to a compact FTIR spectrometer (Arcoptix FT-MIR Rocket 2$6 \mu \mathrm{m})$. The resolution of the spectrometer is here $10 \mathrm{~cm}^{-1}$. The multipass cell is connected to a vacuum pump and a pressure gauge. It is also connected to particles filter to protect the inner part of the cell from dust. Then two gas bottles are connected, which allow to fill the cell with a neutral gas $\left(\mathrm{N}_{2}\right)$ and the analyte gas $\left(\mathrm{CO}_{2}\right.$ or $\left.\mathrm{CH}_{4}\right)$. The neutral gas is used to purge the cell. We can also adjust some binary mixtures composed of $\mathrm{CO}_{2}$ and $\mathrm{CH}_{4}$ by connecting the two corresponding bottles. 


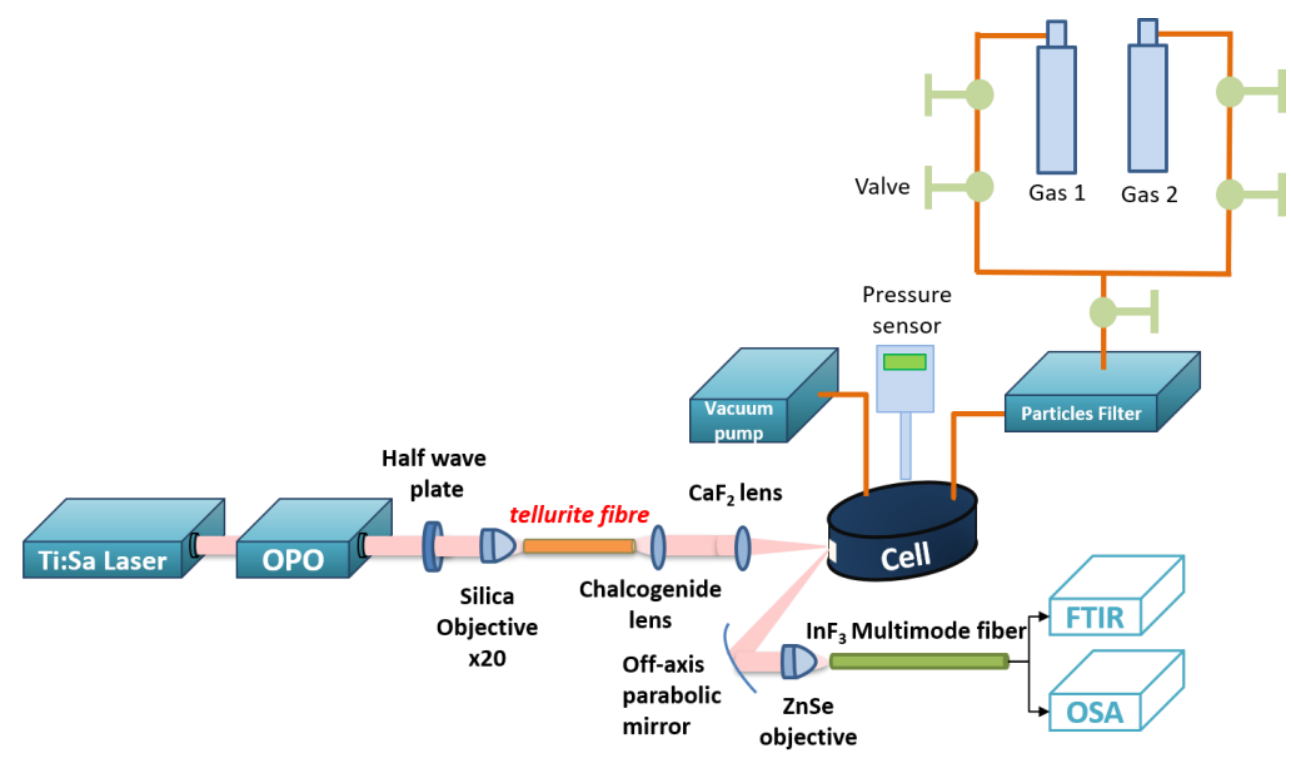

Figure 3. Experimental setup for supercontinuum generation and SAS experiment.

The SC measured at the output of the step-index tellurite fiber is shown in figure 4. A SC spectrum covering at least the 2-3.5 $\mu \mathrm{m}$ window is obtained. At wavelengths beyond $3.5 \mu \mathrm{m}$, the FTIR sensitivity did not allow us to have a suitable signal-to-noise ratio for next SAS measurements. The input pump spectrum is also indicated in figure 4. We superposed the $\mathrm{CH}_{4}$ and $\mathrm{CO}_{2}$ line intensities to clearly locate their spectral positions in comparison with the measured $\mathrm{SC}$. One can easily note that the $\mathrm{CO}_{2}$ absorption band located at $2.7 \mu \mathrm{m}$ and three $\mathrm{CH}_{4}$ absorption bands located at 2.36, 2.58 and $3.27 \mu \mathrm{m}$ (see Table 1) can be analysed in SAS experiments. To this regard, we carried out the following procedure of measurements. First, a reference SC spectrum is recorded when the cell is filled with neutral gas $\left(\mathrm{N}_{2}\right.$ at 1 bar). Next, the cell is purged of $\mathrm{N}_{2}$ with a flow of analyte gas $\left(\mathrm{CH}_{4}\right.$ or $\left.\mathrm{CO}_{2}\right)$ for a few seconds and this gas flow is stopped by closing the last valve. Then, another SC spectrum is measured for several pressure values (e.g., 990, 600, 200, 100 and 50 mbar) by gradually evacuating the cell by means of the vacuum pump.

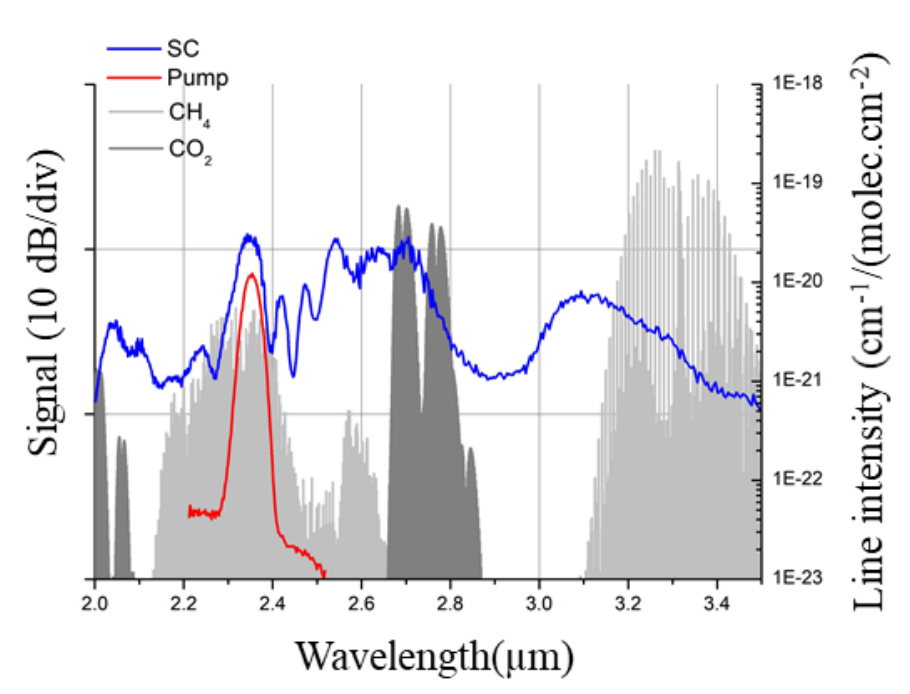

Figure 4. Recorded SC spectrum at the output of the 10-cm-long tellurite fiber (blue curve). Input pump spectrum (red curve). Gray and black lines indicate the $\mathrm{CH}_{4}$ and $\mathrm{CO}_{2}$ absorption bands, respectively.

\section{4. $\mathrm{CO}_{2}$ detection}

Multiple SC spectra were recorded at the output of the gas cell for various $\mathrm{CO}_{2}$ pressures. Figure 5a presents a typical SC measurement for 600 mbar of $\mathrm{CO}_{2}$ (red curve) compared to the SC recorded when the cell is filled with $\mathrm{N}_{2}$ (blue curve). We clearly observe the $\mathrm{CO}_{2}$ absorptions located in the 2.68-2.84 $\mu \mathrm{m}$ range on the SC spectrum after the gas cell, in fairly good 
agreement with the HITRAN database. The measured absorbance $A$ through the cell is then plotted for each gas pressure in figure $5 \mathrm{~b}$ according to the following equation:

$$
A=\log \left(\frac{I_{0}}{I}\right)
$$

where $\mathrm{I}_{0}$ is the reference SC spectrum (cell filled with $\mathrm{N}_{2}$ ) and $\mathrm{I}$ is the intensity of the measured spectrum through the cell filled with $\mathrm{CO}_{2}$. We observe the increase of $\mathrm{CO}_{2}$ absorbance up to $600 \mathrm{mbar}$ in the cell. Between 50 and 600 mbar, we measure the absorbance maximum increasing from 0.38 to 1.45 . For higher pressure, a saturation effect is visible over the full band of interest due to the increasing of the absorption cross section directly related to the gas pressure. There is no saturation for the band located at $2 \mu \mathrm{m}$ because the line intensities at such wavelength are significantly weaker. Then, the evolution of the absorbance is only noticed beyond 600 mbar (i.e., thus requiring a ten times increase of the pressure when comparing to the 2.7- $\mu \mathrm{m}$ absorption band). As reported in Table 1, absorption line intensities of $\mathrm{CO}_{2}$ show three main absorbance bands between

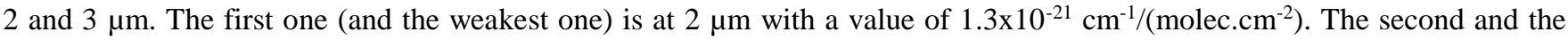
third ones are located at $2.68 \mu \mathrm{m}$ and $2.76 \mu \mathrm{m}$ and have respectively a value of $5.8 \times 10^{-20}$ and $3.9 \times 10^{-20} \mathrm{~cm}^{-1} /\left(\mathrm{molec}^{-2} \mathrm{~cm}^{-2}\right)$. This intensity difference induces a pressure range for which an absorption band is useful. For example, the two absorption bands located at 2.68 and $2.76 \mu \mathrm{m}$ are useful for low pressures as it can be seen between 50 and $600 \mathrm{mbar}$ (see figure 5b). In the case of $\mathrm{CO}_{2}$, it would be useful to get access to the absorption band located at $4.26 \mu \mathrm{m}$ because its high value of absorption intensity $\left(3.5 \times 10^{-18} \mathrm{~cm}^{-1} /\left(\right.\right.$ molec. $\left.\left.\mathrm{cm}^{-2}\right)\right)$ would allow us to detect a lower amount of gas and thus increase sensitivity.
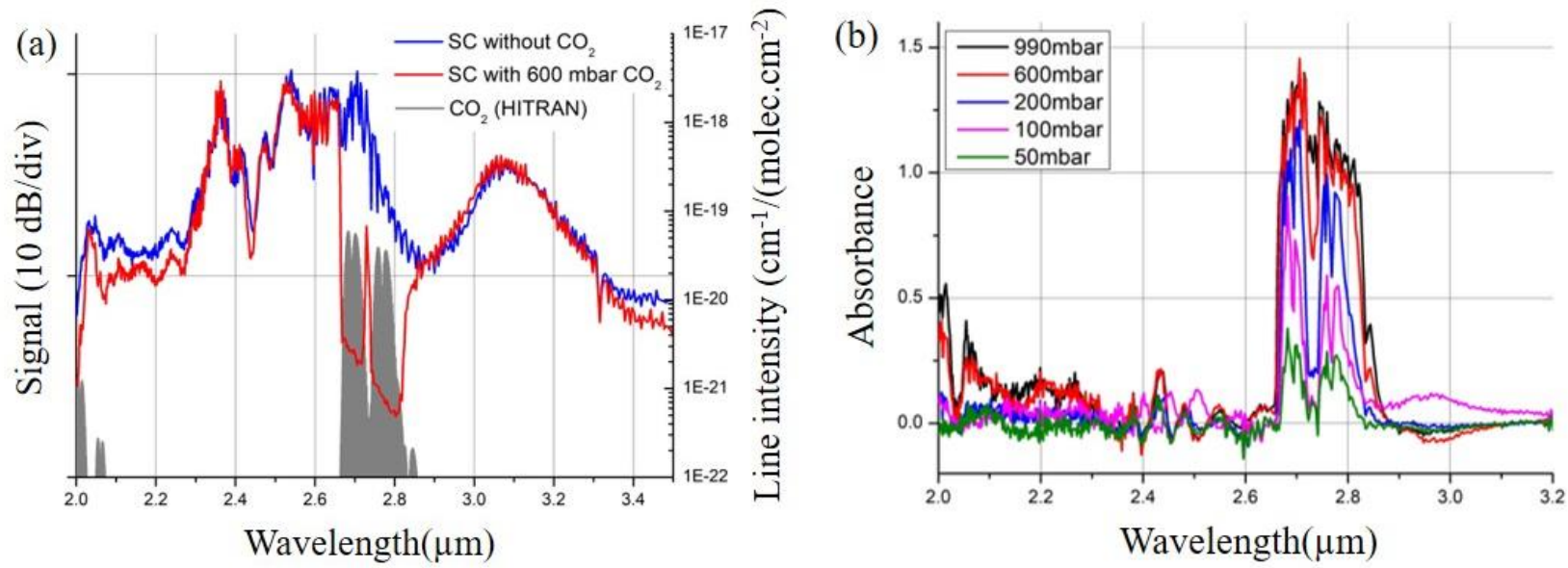

Figure 5. (a) SAS spectra measured at the output of the cell with (red) and without (blue) $\mathrm{CO}_{2}$ gas. (b) Evolution of the measured absorbance of $\mathrm{CO}_{2}$ as a function of pressure.

The line intensities given by HITRAN database for the absorbance bands at $2 \mu \mathrm{m}$ and 2.68-2.84 $\mu \mathrm{m}$ are shown in figure $6 \mathrm{a}$ (grey line), as well as the comparison of the measured absorbance (red) with the predicted absorbance (blue) for the pressure of 600 mbar. In the case of the absorptions located between 2.6 and $2.9 \mu \mathrm{m}$, we observe a good correlation. By measuring the area of this absorption band, we can plot a calibration curve (see figure 6b) to determine the response of our SAS system and retrieve the gas content in next detection measurements. This curve shows the increasing measured area of the absorption band with pressure until reaching a saturation above 300 mbar, with a rather good agreement between theoretical and experimental absorption for all the different pressures. Note that our measurements are not located in the linear regime of our SAS system (here well below 50 mbar). This would require another gas cell configuration for higher sensitivity. For instance, air contains $400 \mathrm{ppm}$ of carbon dioxide which would correspond to $0.4 \mathrm{mbar}$ of $\mathrm{CO}_{2}$ in our cell at atmospheric pressure. As a result, the present sensitivity of our simple SAS system is not high enough for such a low content of $\mathrm{CO}_{2}$ due to low signal-to-noise ratio in our spectral measurements when gas pressure is below 10 mbar. A longer optical path in the gas cell would be required for detecting $\mathrm{CO}_{2}$ in air at these wavelengths. 

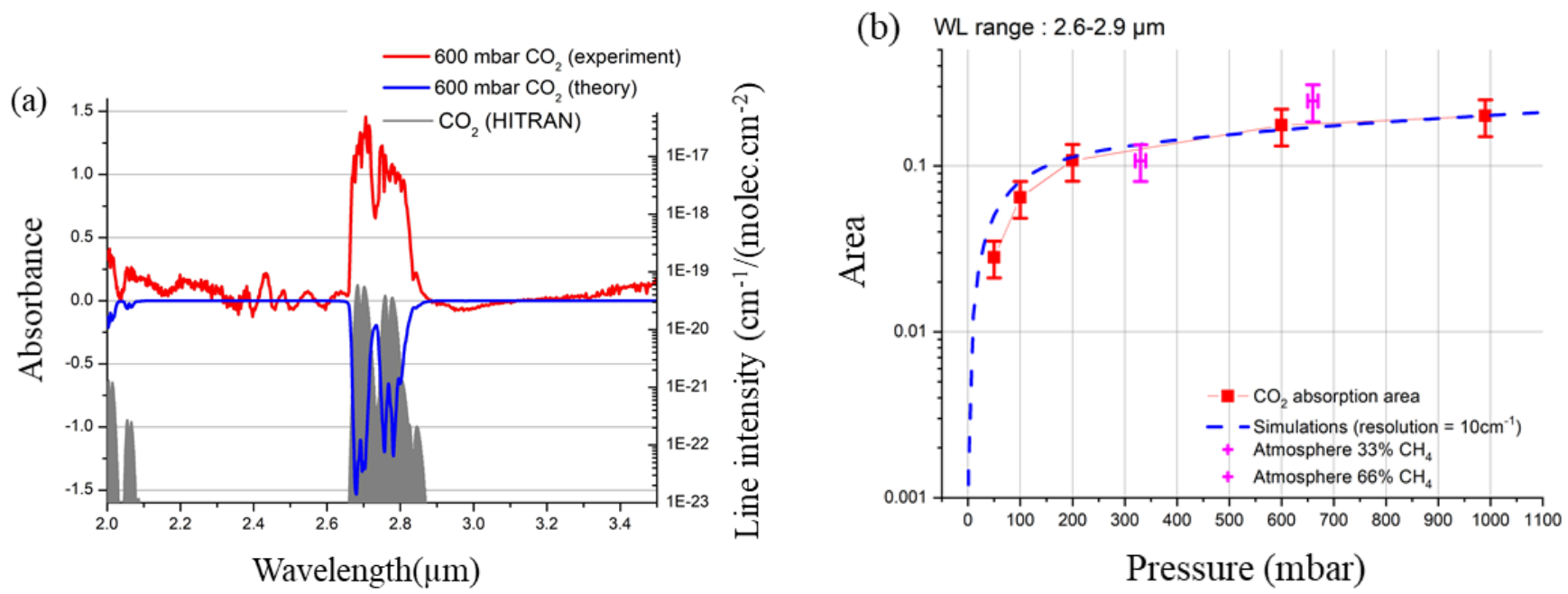

Figure 6. (a) Measured absorbance of $\mathrm{CO}_{2}$ (red) compared to theoretical absorbance calculated from HITRAN database (blue). The grey curve corresponds to the line intensities of $\mathrm{CO}_{2}$ given by HITRAN database. (b) Experimental calibration (red points) of $\mathrm{CO}_{2}$ detection for the 2.6-2.9 $\mu \mathrm{m}$ waveband by our SAS system and comparison with HITRAN predictions (blue dashed line). Magenta points correspond to sensing of gas mixtures.

\section{5. $\mathrm{CH}_{4}$ detection}

The same procedure has been applied for $\mathrm{CH}_{4}$ detection. Figure 7a shows a typical example of SAS measurement, namely two $\mathrm{SC}$ spectra recorded when the multipass cell is filled with $\mathrm{N}_{2}$ or with $300 \mathrm{mbar}$ of $\mathrm{CH}_{4}$. Here we observe three absorption bands centered at $2.3 \mu \mathrm{m}, 2.58 \mu \mathrm{m}$ and $3.27 \mu \mathrm{m}$, respectively (see also Table 1). Corresponding measured absorbance as a function of gas pressure is depicted in figure $7 \mathrm{~b}$. We observe again a continuous increase of absorbance with pressure until reaching a saturation beyond $600 \mathrm{mbar}$, in particular for the absorption bands centered on 2.3 and $3.27 \mu \mathrm{m}$. Those differences on the useful range of pressures is related with a strong difference between $\mathrm{CH}_{4}$ line intensities in accordance with HITRAN database. Indeed, the $\mathrm{CH}_{4}$ absorption line intensities at $2.3 \mu \mathrm{m}$ are about $6.3 \times 10^{-21} \mathrm{~cm}^{-1} /\left(\right.$ molec. $\left.\mathrm{cm}^{-2}\right)$ instead of $1.3 \times 10^{-21} \mathrm{~cm}^{-1} /(\mathrm{molec} \mathrm{cm}-2)$ at 2.6 $\mu \mathrm{m}$. Beyond $3 \mu \mathrm{m}$, the absorption intensity has a value around $2.1 \times 10^{-19} \mathrm{~cm}^{-1} /\left(\right.$ molec.cm $\left.{ }^{-2}\right)$. Thus, $\mathrm{CH}_{4} \mathrm{SAS}$ measurement beyond $3 \mu \mathrm{m}$ leads to higher sensitivity and allow detection of lower gas content.
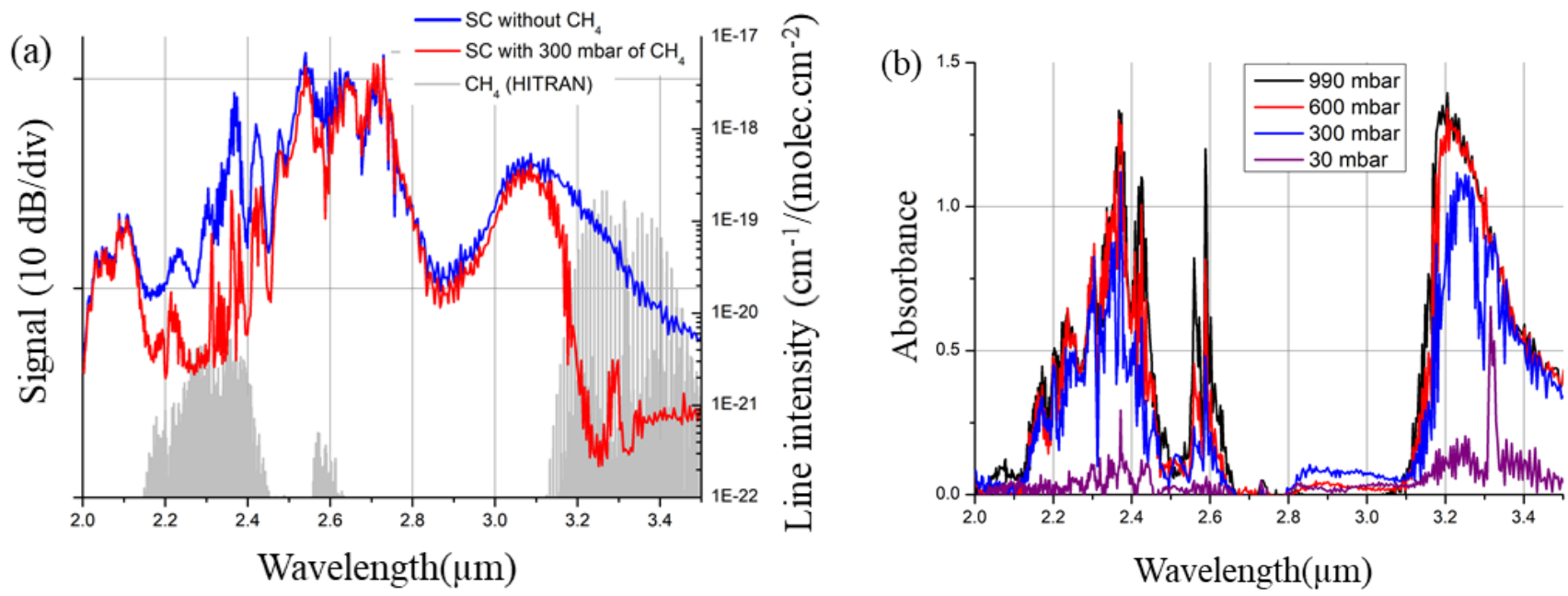

Figure 7. (a) SAS spectra measured at the output of the cell with (red) and without (blue) $\mathrm{CH}_{4}$ gas. (b) Evolution of the measured absorbance of $\mathrm{CH}_{4}$. 
The line intensities given by HITRAN database for the absorbance bands are shown in figure 8a (grey line), as well as the comparison of the measured absorbance (red) with the predicted absorbance (blue) for the pressure of 200 mbar. A calibration curve is plotted by measuring the area of the absorption band beyond $3 \mu \mathrm{m}$ as a function of gas pressure in order to qualify the response of our SAS system for $\mathrm{CH}_{4}$ (see figure 8b). This waveband is chosen since it significantly differs from the $\mathrm{CO}_{2}$ absorption band studied above, thus facilitating the investigation of gas mixtures in the following. The analysis of area of the long-wavelength absorption band indicates a saturation effect that appears around 100 mbar (see figure $8 \mathrm{~b}$ ). The prediction from HITRAN data shows that this saturation effect occurs even at lower pressures (before 50 mbar of $\mathrm{CH}_{4}$ ). As in the case of $\mathrm{CO}_{2}$ measurements, our cell configuration doesn't correspond to a linear regime.
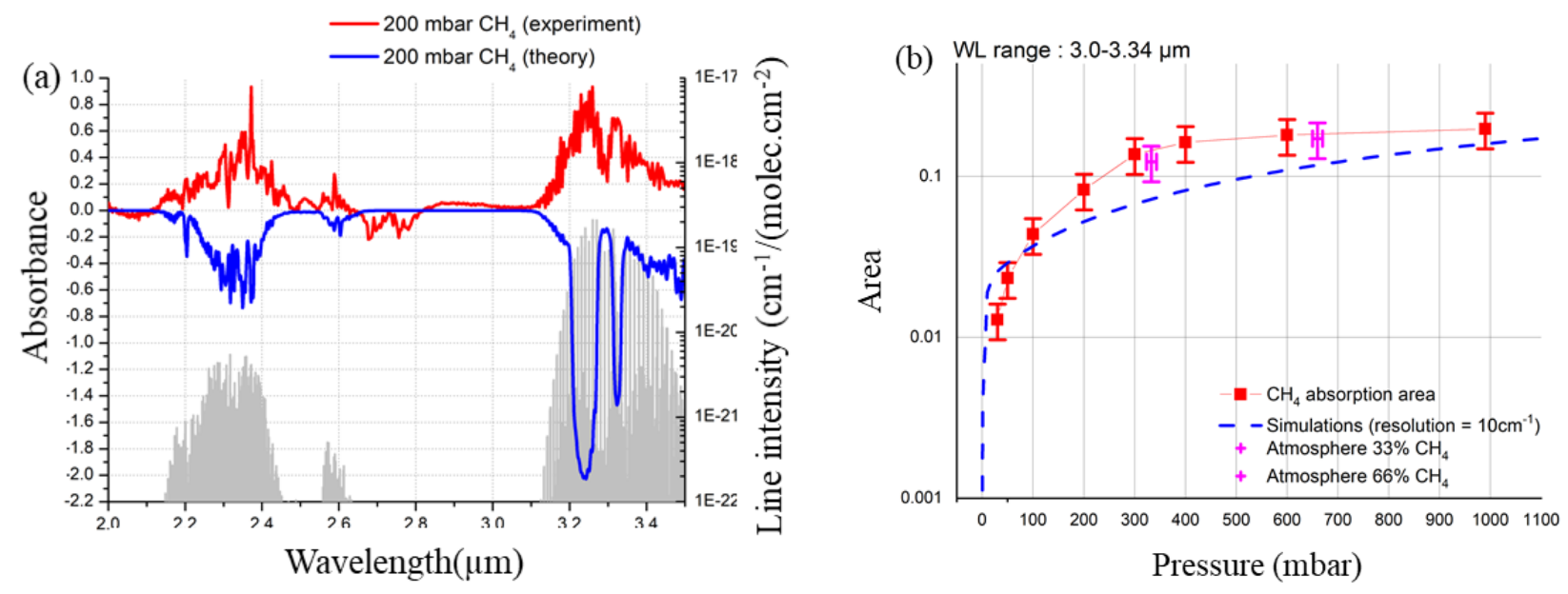

Figure 8. (a) Measured absorbance of $\mathrm{CH}_{4}$ (red) compared to theoretical absorbance given by HITRAN database (blue). The grey curve corresponds to the line intensities of $\mathrm{CH} 4$ given by HITRAN database. (b) Calibration curves of $\mathrm{CH}_{4}$ detection by our SAS system for the 3.0-3.34 $\mu \mathrm{m}$ waveband by our SAS system and compared with HITRAN predictions (blue dashed line). Magenta points correspond to sensing of gas mixtures.

\section{Detection of gas mixtures}

As a proof of principle, we demonstrate the capability of our simple SAS system to detect and differentiate gases in a binary mixture. Two gas mixtures composed of $\mathrm{CH}_{4}$ and $\mathrm{CO}_{2}$ are analysed at a pressure of 1 bar in our multipass cell. Figure 9 shows the absorbance measurements for $66 \%$ of $\mathrm{CO}_{2}$ with $33 \%$ of $\mathrm{CH}_{4}$ (red curve) and $33 \%$ of $\mathrm{CO}_{2}$ with $66 \%$ of $\mathrm{CH}_{4}$ (blue curve). All the absorption signatures detected earlier are observed and their discrimination is possible due to negligible spectral overlap. The absorption band between 2.65-2.85 $\mu$ m corresponds to $\mathrm{CO}_{2}$ while the absorption bands between 2,15-2,45 $\mu \mathrm{m}$, around 2,58 and beyond $3 \mu \mathrm{m}$ correspond to $\mathrm{CH}_{4}$. As expected, the $\mathrm{CO}_{2}$-rich atmosphere has an absorbance at 2.65-2.85 $\mu \mathrm{m}$ higher than in the $\mathrm{CH}_{4}$-rich one. We note that the $2-\mu \mathrm{m} \mathrm{CO}_{2}$-related absorption band is absent in the $\mathrm{CH}_{4}$-rich atmosphere. On the other hand, this absorption band is easily monitored for the $\mathrm{CO}_{2}$-rich atmosphere. The same phenomenon is noticed for the $2.58 \mu \mathrm{m} \mathrm{CH}_{4}$ related absorption band, which can be properly monitored mainly in $\mathrm{CH}_{4}$-rich atmosphere. Finally, for a pressure above 330 mbar for each gas respectively, we have access to all absorption bands in the wavelength range of interest. Then we check the reliability of our SAS system by indicating the corresponding absorption areas of the two gas mixtures on each previous calibration curves of $\mathrm{CH}_{4}$ and $\mathrm{CO}_{2}$ (see magenta points on figures $6 \mathrm{~b}$ and $8 \mathrm{~b}$ ). We observe that our measurements are consistent and that this developed SAS system can simultaneously detect $\mathrm{CO}_{2}$ and $\mathrm{CH}_{4}$ from their absorption bands between 2 and 3.5 $\mu \mathrm{m}$ and quantify the gas mixture. From these proof of principle experiments, a way to increase significantly the sensitivity of the set-up would be to increase the optical path of the multipass cell. 


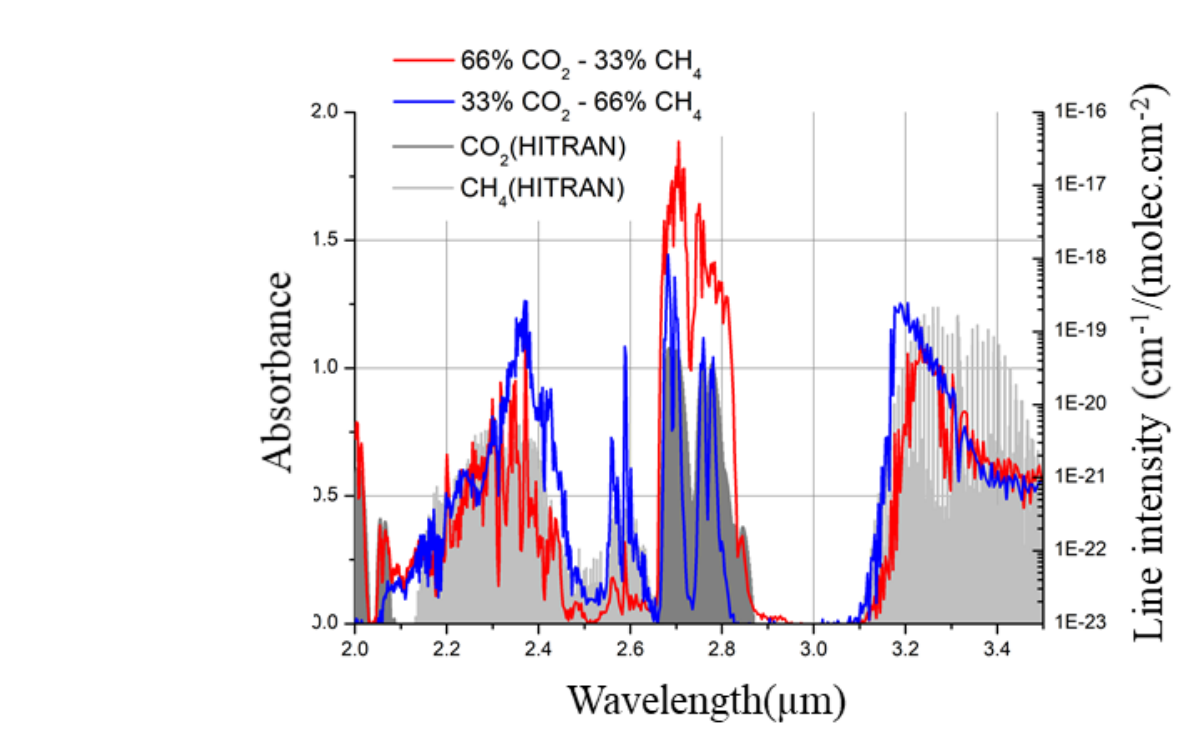

Figure 9: Absorbance curves of two gas mixtures for total pressure of 1-bar: $66 \%$ of $\mathrm{CO} 2$ and $33 \%$ of $\mathrm{CH} 4$ (red curve) and $33 \%$ of $\mathrm{CO} 2$ and $66 \%$ of $\mathrm{CH} 4$ (blue curve)

\section{Conclusion}

In conclusion, we have investigated mid-infrared gas sensing by means of a simple configuration of supercontinuum absorption spectroscopy based on a high-repetition-rate mid-infrared supercontinuum light generated through nonlinear propagation of 200-fs pulses in a 10-cm-long segment of step-index tellurite fiber. In particular, a compact multipass cell is used for analyzing

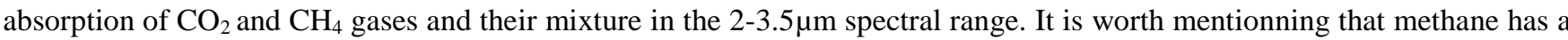
polluting power 32 times higher than $\mathrm{CO}_{2}[23]$ and it deserves to be easily measured as well as $\mathrm{CO}_{2}$. In the case of $\mathrm{CO}_{2}$, there is about $400 \mathrm{ppm}$ of $\mathrm{CO}_{2}$ in the air, which would correspond to a $\mathrm{CO}_{2}$ pressure in the cell of our experimental set-up of 0.4 mbar. In the case of methane its atmospheric concentration is about $1800 \mathrm{ppb}$ corresponding to a cell $\mathrm{CH}_{4}$ pressure of $1.8 \mu \mathrm{bar}$ ). These values are below the sensitivity threshold of our set-up. However, this work is a proof-of-principle experiment which illustrates the feasibility of multiple detection of greenhouse gases using SAS method. It can be much improved in particular by incresasing the optical path of the sensing cell and by using a more intense and larger supercontinuum up to $5.3 \mu \mathrm{m}$ which is reachable with this type of fibers [17]. In particular, in this case, the wavelength of $4.26 \mu \mathrm{m}$ may be reached allowing to measure low concentrations of $\mathrm{CO}_{2}$ and $\mathrm{CH}_{4}$. In addition, we can also mention that we use free space coupling at the input and output of our tellurite fiber. An optimization towards an all-fiber spliced device would also improve the set-up as well as the use of new pulsed fs fibered lasers entering the market as a pump source. In addition, by increasing the signal to noise ratio of our set-up, it will be possible to work at low pressures in the linear regime of the detection. Finally, this proof of principle experiment needs now to mature to develop its potential as a new multi-gas infrared optical sensor.

\section{Acknowledgements}

We acknowledge the fnancial support of the French Investissements d'Avenir program (ISITE-BFC ANR-15-IDEX-0003, SCUVIRA project), the Council of the French Région Bourgogne Franche-Comté, the European program FEDER, through the grant 'Jeune Chercheur Entrepreneur' scheme, and the French CNRS and the Japanese JSPS through the PRC CNRS-JSPS Program.

\section{References}

[1] Ferreira M F et al 2017 J. Opt. 19083001

[2] Zhao Z et al 2017 Laser Photonics Rev. 111700005

[3] Petersen C R et al 2018 Opt. Lett. 43 999-1002 
[4] https://hitran.org/

[5] Hughes R et al 2014 J Quant Spectrosc Radiat Transf 148 18-21

[6] Brow D M et al 2008 Opt. Express 16 8457-8471

[7] Nakaema W M et al 2011 Sensors 11 1620-1640

[8] Hult J et al 2007 Opt. Express 15 11385-11395

[9] Dupont S et al 2014 Las. Phys. Lett. 11075601

[10] Amiot C et al 2017 Appl. Phys. Lett. 111061103

[11] Mikkonen T et al 2018 Opt Lett 43 5094-5097

[12] Dasa M K et al 2020 Photoacoustics 18100163

[13] Strutynski C et al 2016 Laser Phys Lett 13075402

[14] Strutynski C et al 2017 Opt. Fiber Technol. 38 154-159

[15] Strutynski C et al 2017 Opt. Lett. 42 247-250

[16] Froidevaux P et al 2018 Appl. Sci. 81875

[17] Kedenburg S et al 2017 JOSA B 34 601-607

[18] Strutynski C et al 2016 JOSA B 33 D12-D18

[19] O’Donnell M et al 2003 J. Non-Cryst. Solids 331 48-57

[20] Massera J et al 2011 J. Am. Ceram. Soc. 94 130-136

[21] Savelii I et al 2013 Opt. Mater. 35 1595-1599

[22] Humbach O et al 1996 J. Non-Cryst. Solids 203 19-26

[23] Etminan M et al 2016 Geophys. Res. Lett. 43 12,614-12,623 